\title{
Retrospective Comparison of mFOLFOXIRI With XELOX/SOX as Neoadjuvant Chemotherapy for Locally Advanced Rectal Cancer
}

\author{
HIROYUKI KODAMA ${ }^{1}$, TETSUJI TERAZAWA ${ }^{2}$, YASUNOBU ISHIZUKA ${ }^{1}$, HIROKI YUKAMI $^{1}$, \\ MASAHIKO AOKI ${ }^{1}$, TAKAHIRO MIYAMOTO ${ }^{2}$, TOSHIFUMI YAMAGUCHI ${ }^{2}$, FUTUKARO SHIMAMOTO $^{2}$, \\ TAKAYUKI KII ${ }^{2}$, MASAHIRO GOTO ${ }^{2}$, HIROKI HAMAMOTO ${ }^{3}$, WATARU OSUMI ${ }^{3}$, MASASHI YAMAMOTO $^{3}$, \\ KEITARO TANAKA ${ }^{3}$, JYUNJI OKUDA ${ }^{3}$, KAZUHISA UCHIYAMA ${ }^{3}$ and KAZUHIDE HIGUCHI ${ }^{1}$ \\ ${ }^{1}$ Department of Gastroenterology, Osaka Medical College, Osaka, Japan; \\ ${ }^{2}$ Cancer Chemotherapy Center, Osaka Medical College Hospital, Osaka, Japan; \\ ${ }^{3}$ Department of General and Gastroenterological Surgery, Osaka Medical College, Osaka, Japan
}

\begin{abstract}
Background/Aim: Neoadjuvant chemotherapy without radiation (NAC) shows favorable outcomes for locally advanced rectal cancer ( $L A R C)$, however, the optimal regimen has not been determined yet. This study aimed to compare the efficacy and safety of oxaliplatin, irinotecan, folinic acid, and 5-fluorouracil (mFOLFOXIRI) with capecitabine/S-1 and oxaliplatin (XELOX/SOX) in rectal cancer patients. Patients and Methods: We retrospectively examined patients with LARC who received MFOLFOXIRI or XELOX/SOX as NAC. Results: Between January 2015 and July 2019, 49 patients received $m F O L F O X I R I$ and 37 patients received XELOX/SOX. The pathological response rates (over two-thirds affected tumor area) were $36.7 \%$ and $40.5 \%$ in the $\mathrm{mFOLFOXIRI} \mathrm{and}$ XELOX/SOX groups, respectively. Grade $3 / 4$ neutropenia was experienced by $45.0 \%$ of the patients in the MFOLFOXIRI group and $8.0 \%$ in the XEOX/SOX group. Conclusion: Although pathological responses were comparable between two groups, mFOLFOXIRI tended to be more toxic compared to XELOX/SOX as NAC for LARC.
\end{abstract}

Colorectal cancer is currently the third most commonly diagnosed cancer (1). In one-third of the patients the cancer is located in the rectum (1). The standard treatment for

This article is freely accessible online.

Correspondence to: Tetsuji Terazawa, Department of Cancer Chemotherapy Center, Osaka Medical College Hospital, 2-7 Daigaku machi, Takatsuki City, Osaka 569-8686, Japan. Tel: +81 726831221, Fax: +81 726846778, e-mail: terasawat@osaka-med.ac.jp

Key Words: Locally advanced rectal cancer, mFOLFOXIRI XELOX, SOX, neoadjuvant, chemotherapy. locally advanced rectal cancer (LARC, T3-4 Nany, M0) is neoadjuvant fluoropyrimidine-based chemotherapy with radiation, followed by total mesorectal excision surgery plus adjuvant chemotherapy (2-4). Although chemotherapy with radiation reduces the risk of local recurrence (5), it does not improve disease-free or overall survival (6). Moreover, chemotherapy with radiation often causes complications such as sexual, urinary, or bowel dysfunctions (7). Therefore, strategies of neoadjuvant chemotherapy without radiation have been an attempt not only to control distant micrometastases but also to reduce radiation toxicity.

Recently, several studies about neoadjuvant chemotherapy without radiation showed promising results. A pilot study with folinic acid, 5-fluorouracil (5-FU), and oxaliplatin (LOHP) (mFOLFOX6) plus bevacizumab for LARC showed that the 4-year disease-free survival was $84 \%$ (8). Furthermore, the phase III FOWARC study, which compared in patients with LARC neoadjuvant FOLFOX with or without radiation, has provided similar rates of local recurrence $(7.0 \%$ and $8.3 \%$, respectively) and 3 -year diseasefree survival $(77.2 \%$ and $73.5 \%$, respectively) in the two study groups, although the radiation group had a higher rate of anastomotic fistula $(18.1 \%$ vs. $7.9 \%)(9,10)$. Despite this, there is still room for improvement so as to determine the best regimen for neoadjuvant chemotherapy.

Capecitabine and L-OHP (XELOX) or S-1 and L-OHP (SOX) have been standard treatments for metastatic colorectal cancer worldwide, not inferior to FOLFOX, and do not require the placement of a central venous port (11, 12). Moreover, in the IDEA and ACHIEVE studies, XELOX resulted in superior efficacies compared to FOLFOX in adjuvant settings $(13,14)$.

The triplet regimen: folinic acid, 5-FU, L-OHP, and irinotecan (FOLFOXIRI) has shown a higher response rate 
compared to a doublet regimen in metastatic colorectal cancer (15) and was anticipated to achieve conversion surgery for patients who have been diagnosed as unresectable at baseline. However, the incidence of grade 3 or 4 leukopenia was high with the original FOLFOXIRI dosage. Despite comparable efficacy, the modified (m)FOLFOXIRI regimen was less toxic than the original one $(16,17)$.

Taking all the above into account, we retrospectively investigated the efficacy and safety of mFOLFOXIRI and $\mathrm{XELOX/SOX}$ as neoadjuvant therapies for LARC.

\section{Patients and Methods}

Patients. We retrospectively reviewed the medical records of patients who had been diagnosed with LARC and received mFOLFOXIRI or XELOX/SOX as a neoadjuvant treatment followed by laparoscopic surgery between February 2015 and July 2019 at Osaka Medical College Hospital, Osaka, Japan. We selected patients who met the following criteria: i) age 20 years or older, ii) histologically confirmed rectal adenocarcinoma, iii) location in the middle $(\mathrm{Ra})$, lower $(\mathrm{Rb})$ rectum or the proctodeum (P), iv) cT2N+, cT3-4 Nany and M0, v) no prior chemotherapy or radiotherapy; vi) Eastern Cooperative Oncology Group performance status 0 or 1 , and vii) adequate renal (serum creatine clearance $<50 \mathrm{ml} / \mathrm{min}$ ), liver (aspartate and alanine aminotransferases $\leq 3 \times$ the upper limit of the normal range), hematologic (hemoglobin $\geq 9.0 \mathrm{~g} / \mathrm{dl}$ ), and bone marrow (neutrophil count $>1,500$ cells $/ \mathrm{mm}^{3}$ and platelet count $>100,000$ cells $/ \mathrm{mm}^{3}$ ) functions. Patients with metastatic disease, colon cancer, and presence of other cancers were excluded.

This study was performed in agreement with the ethical principles described in the Declaration of Helsinki. The institutional review board of Osaka Medical College Hospital approved this study protocol (No. 2915). Written informed consent was obtained from all participants.

Baseline assessments included: i) clinical examination, ii) total colonoscopy, iii) chest and abdominopelvic computed tomography, and iv) pelvic magnetic resonance imaging. A positive lymph node was defined as $\geq 5 \mathrm{~mm}$ in short diameter or irregular shape on imaging. All patients were staged using the $8^{\text {th }}$ edition of the Union for International Cancer Control classification.

Neoadjuvant chemotherapy. mFOLFOXIRI (L-OHP $85 \mathrm{mg} / \mathrm{m}^{2}$, irinotecan $150 \mathrm{mg} / \mathrm{m}^{2}$, folinic acid $200 \mathrm{mg} / \mathrm{m}^{2}$ on day 1 , followed by 5 -FU $2400 \mathrm{mg} / \mathrm{m}^{2}$ over 46 -hour continuous infusion) was administered every 2 weeks for 4 to 6 cycles depending on the patient's tolerance or the doctor's decision. XELOX (capecitabine $2000 \mathrm{mg} / \mathrm{m}^{2}$ for 14 days and L-OHP $130 \mathrm{mg} / \mathrm{m}^{2}$ on day 1) or SOX (S-1 $80 \mathrm{mg} / \mathrm{m}^{2}$ for 14 days and L-OHP $130 \mathrm{mg} / \mathrm{m}^{2}$ on day 1 ) was administered every 3 weeks for 4 cycles.

Surgery and adjuvant chemotherapy. The laparoscopic surgery with total mesorectal excision was performed 3-6 weeks after neoadjuvant chemotherapy. If the lateral pelvic lymph node was positive, lateral pelvic dissection was added. The neoadjuvant and adjuvant chemotherapies were planned for a total time of 6 months. The fluoropyrimidine-based regimen was administered as adjuvant chemotherapy.
Table I. Patient characteristics.

\begin{tabular}{|c|c|c|}
\hline & $\begin{array}{c}\text { mFOLFOXIRI } \\
\mathrm{n}=49(\%)\end{array}$ & $\begin{array}{c}\text { XELOX/SOX } \\
\mathrm{n}=37(\%)\end{array}$ \\
\hline \multicolumn{3}{|l|}{ Age, years } \\
\hline Median (range) & $64(37-80)$ & $64(33-79)$ \\
\hline \multicolumn{3}{|l|}{ Gender } \\
\hline Male/Female & $32(65.3) / 17$ (34.7) & $25(67.6) / 12(32.4)$ \\
\hline \multicolumn{3}{|l|}{ ECOG PS } \\
\hline $0 / 1$ & $46(94.0) / 3(6.0)$ & $18(48.7) / 19(51.3)$ \\
\hline \multicolumn{3}{|l|}{ Histology } \\
\hline Tub & $44(90.0)$ & $36(97.3)$ \\
\hline Pap & $1(2.0)$ & $1(2.7)$ \\
\hline Por & $1(2.0)$ & 0 \\
\hline Muc & $3(6.0)$ & 0 \\
\hline \multicolumn{3}{|l|}{ Location } \\
\hline $\mathrm{Ra} / \mathrm{Rb} / \mathrm{P}$ & $4(8.2) / 44(90.0) / 1(1.8)$ & 0/37 (100)/0 \\
\hline \multicolumn{3}{|l|}{ Clinical $\mathrm{T}$ stage } \\
\hline cT2/cT3/cT4a/cT4b & $\begin{array}{l}2(4.1) / 29(59.2) / \\
9(18.4) / 10(20.4)\end{array}$ & $\begin{array}{l}2(5.4) / 22(59.5) / \\
9(24.3) / 4(10.8)\end{array}$ \\
\hline \multicolumn{3}{|l|}{ Clinical N stage } \\
\hline $\mathrm{cN} 0 / \mathrm{cN} 1 / \mathrm{cN} 2 \mathrm{a} / \mathrm{cN} 2 \mathrm{~b}$ & $\begin{array}{c}13(26.5) / 26(53.1) / \\
6(12.2) / 4(8.2)\end{array}$ & $\begin{array}{c}10(27.0) / 20(54.0) / \\
3(8.2) / 4(10.8)\end{array}$ \\
\hline \multicolumn{3}{|l|}{ TNM stage } \\
\hline II/IIIA/IIIB/IIIC & $\begin{array}{c}13(26.5) / 2(4.1) / \\
24(49.0) / 10(20.4)\end{array}$ & $\begin{array}{l}11(29.8) / 2(5.4) / \\
17(45.9) / 7(18.9)\end{array}$ \\
\hline $\begin{array}{l}\text { Baseline CEA level } \\
(\mathrm{ng} / \mathrm{ml}) \\
\leq 5.0 />5.0 / \text { unknown }\end{array}$ & $\begin{array}{c}27(55.1) / 21(42.8) / \\
1(2.1)\end{array}$ & $18(48.7) / 19(51.3) / 0$ \\
\hline $\begin{array}{l}\text { Lateral lymph node } \\
\text { metastases }\end{array}$ & & \\
\hline Yes & $9(18.4)$ & $12(32.4)$ \\
\hline NAC regimen & mFOLFOXIRI: 49 (100) & $\begin{array}{l}\text { XELOX: } 35(94.5) \\
\text { SOX: } 2(5.4)\end{array}$ \\
\hline
\end{tabular}

ECOG PS: Eastern Cooperative Oncology Group performance status; tub: tubular adenocarcinoma; pap: papillary adenocarcinoma; por: poorly differentiated adenocarcinoma; muc: mucinous adenocarcinoma; Ra: middle rectum; Rb: lower rectum; P: proctodeum; CEA: carcinoembryonic antigen; NAC: neoadjuvant chemotherapy without radiation.

Study assessments. The histological tumor response grade of the neoadjuvant chemotherapy was determined according to the Japanese Society for Cancer of the Colon and Rectum (JSCCR): i) grade 0, no regression; ii) grade 1a, minimal effect (necrosis less than onethird of the lesion); iii) grade $1 \mathrm{~b}$, mild effect (necrosis less than twothirds but at least one-third of the lesion); iv) grade 2, moderate effect (necrosis more than two-thirds of the lesion); and v) grade 3, no tumor cells (pathologic complete response, pCR) (18).

In our study, pathological response was defined as grade 2 or better. Downstaging was defined as an improvement of the pathological $\mathrm{T}$ or $\mathrm{N}$ factors compared to the clinical $\mathrm{T}$ or $\mathrm{N}$ factors at baseline. Relative dose intensity was calculated as the actual divided by the planned dose intensity. We also assessed recurrencefree survival, which was defined as the time from the day of operation to recurrence or death from any cause. Adverse events were graded according to the Common Terminology Criteria for Adverse Events (CTCAE) version 4.0-Japan Clinical Oncology 


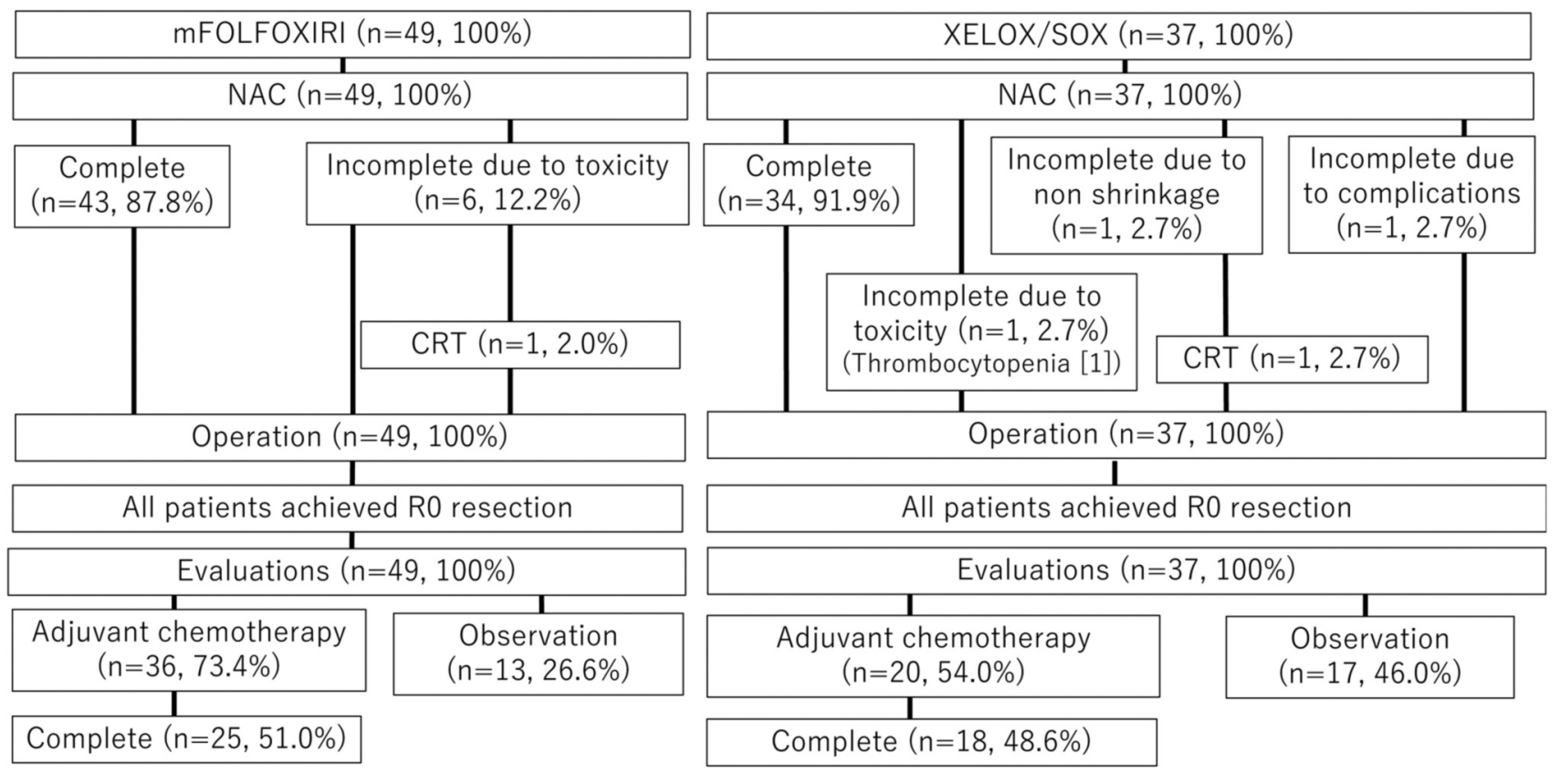

Figure 1. Flow diagram of this study.

edition (19), and surgical complications were graded according to the Clavien-Dindo criteria version 2.0-Japan Clinical Oncology edition (20).

Statistical analysis. The data cut-off was February 2020. We compared pathological response and downstaging rate using the two-sided Fisher's exact test. We also used Kaplan-Meier survival curves to calculate the recurrence-free survival, and the log-rank test to compare treatment effects. For all analyses, two-sided $p$ Values $<0.05$ were considered statistically significant. All statistical analyses were performed using JMP Pro, version 14 (SAS Institute Japan Ltd., Tokyo, Japan).

\section{Results}

Patient characteristics. From February 2015 to July 2019, a total of 86 patients received neoadjuvant chemotherapy for LARC and met the inclusion and exclusion criteria. Of these enrolled patients, 49 patients received mFOLFOXIRI between February 2015 and June 2017, whereas 35 and 2 patients received XELOX and SOX, respectively, between April 2017 and July 2019 as neoadjuvant chemotherapy. Table I shows the patient characteristics. The median age was 64 (range $=37-80$ ) years in the mFOLFOXIRI group and 64 (range=33-79) years in the XELOX/SOX group. In the mFOLFOXIRI group, the tumor locations of 44 patients (89\%) were classified as $\mathrm{Rb}$ and of one patient (2\%) as $\mathrm{P}$, whereas all 37 patients $(100 \%)$ of the XELOX/SOX group had $\mathrm{Rb}$ as a tumor location. In the mFOLFOXIRI group, 9 $(18 \%)$ and $10(20 \%)$ patients were cT4a and cT4b, respectively, whereas 9 patients $(24 \%)$ were cT4a and 4 patients $(11 \%)$ were cT4b in the XELOX/SOX group.

Figure 1 displays the flow diagram of this study. A total of 43 patients $(87.8 \%)$ and 34 patients $(91.9 \%)$ completed the planned neoadjuvant chemotherapy in the mFOLFOXIRI and the XELOX/SOX groups, respectively. Six patients (12.2\%) of the mFOLFOXIRI group discontinued the treatment due to toxicity effects: i) one patient due to febrile neutropenia, ii) two patients due to diarrhea, and iii) three patients due to anorexia. In the XELOX/SOX group, three patients $(8.1 \%) \mathrm{did}$ not complete the treatment cycles: i) one patient due to thrombocytopenia, ii) one patient due to lack of efficacy and iii) one patient due to a thromboembolic event. One patient in each of the mFOLFOXIRI and XELOX/SOX groups received radiation in addition. All patients in both groups underwent surgery. Thirteen patients $(26.6 \%)$ did not receive adjuvant chemotherapy in the mFOLFOXIRI group: i) seven patients due to pathological or clinical N0, ii) three patients due to postoperative complications and iii) three patients out of choice, whereas 17 patients $(46.0 \%)$ did not receive adjuvant chemotherapy in the XELOX/SOX group: i) nine patients due to pathological or clinical N0, ii) two patients due to postoperative complications and iii) six patients out of choice.

Treatment exposure and surgical results. The relative dose intensity of neoadjuvant treatment is shown in Table II. The median number of cycles was 4 (range=1-6) in the mFOLFOXIRI group and 4 (range=2-4) in the XELOX/SOX group. In the mFOLFOXIRI group, nine patients each 
Table II. Treatment exposure.

\begin{tabular}{|c|c|c|c|c|c|}
\hline & \multicolumn{3}{|c|}{$\begin{array}{c}\text { mFOLFOXIRI } \\
\mathrm{n}=49(\%)\end{array}$} & \multicolumn{2}{|c|}{$\begin{array}{c}\text { XELOX/SOX } \\
n=37(\%)\end{array}$} \\
\hline & L-OHP & IRI & $5-\mathrm{FU}$ & L-OHP & capecitabine/S-1 \\
\hline RDI (range) & $\begin{array}{c}0.98 \\
(0.60-1.01)\end{array}$ & $\begin{array}{c}0.98 \\
(0.56-1.01)\end{array}$ & $\begin{array}{c}0.98 \\
(0.65-1.01)\end{array}$ & $\begin{array}{c}0.90 \\
(0.60-1.00)\end{array}$ & $\begin{array}{c}0.99 \\
(0.74-1.01)\end{array}$ \\
\hline Course (range) & $4(1-6)$ & $4(1-6)$ & $4(1-6)$ & $4(2-4)$ & $4(2-4)$ \\
\hline Reduced starting dose & $1(2.0)$ & 0 & 0 & 0 & 0 \\
\hline Dose reduction during treatment & $9(18.3)$ & $9(18.3)$ & $5(10.2)$ & $24(64.8)$ & $5(13.5)$ \\
\hline
\end{tabular}

L-OHP: Oxaliplatin; IRI: irinotecan; 5-FU: 5-fluorouracil; RDI: relative dose intensity.

(18.3\%) reduced L-OHP and irinotecan doses, whereas for 5 -FU, this was observed in five patients (10.2\%). By contrast, 24 patients $(64.8 \%)$ and 5 patients $(13.5 \%)$ reduced L-OHP and capecitabine or S-1 doses, respectively, in the XELOX/SOX group. Regarding the surgical results, 13 patients $(26.5 \%)$ in the mFOLFOXIRI group and 12 patients $(32.4 \%)$ in the XELOX/SOX group also underwent lateral lymph node dissection. All patients in both groups achieved $\mathrm{R} 0$ resections (Table III).

Efficacy. Table IV shows the efficacies of the neoadjuvant therapies. Eighteen patients $(36.7 \%)$ achieved a pathological response, including two patients $(4.8 \%)$ with pCR, in the mFOLFOXIRI group, whereas 15 patients $(40.5 \%)$, including 5 patients $(13.5 \%)$ with pCR, presented in the XELOX/SOX group a pathological response ( $p=0.8236$ by two-sided Fisher's exact test). Downstaging was observed in 31 patients $(63.2 \%)$ in the mFOLFOXIRI group and 31 patients $(83.8 \%)$ in the XELOX/SOX group $(p=0.0516)$. The median values for the follow-up time were 36.5 months in the mFOLFOXIRI group and 12.0 months in the XELOX/SOX group. Recurrence was observed in 13 patients $(26.5 \%)$ in the mFOLFOXIRI group: i) one patient $(2.0 \%)$ with local recurrence, ii) two patients $(4.1 \%)$ with liver, iii) five patients $(10.2 \%)$ with lung, iv) one patient $(2.0 \%)$ with peritoneum, and v) four patients $(8.2 \%)$ with lymph node involvement. In the XELOX/SOX group, seven patients (18.9\%) had tumor recurrence: i) one patient $(2.7 \%)$ with local recurrence, ii) five patients $(13.5 \%)$ with lung and iii) one patient $(2.7 \%)$ with liver. The 3-year recurrence-free survival rate was $69.4 \%(95 \%$ confidence interval $(\mathrm{CI})=55.2$ $80.6 \%$ ) in the mFOLFOXIRI group. The corresponding value for the XELOX/SOX group could not be determined due to the shorter follow-up time (Figure 2). The 1-year recurrence-free survival rates were $85.7 \%(95 \% \mathrm{CI}=72.9$ $93.0 \%)$ in the mFOLFOXIRI group and $76.5 \%$ $(95 \% \mathrm{CI}=57.7-88.6 \%)$ in the XELOX/SOX group $(p=0.481$ by log-rank test); however, these are only preliminary data due to the short-term outcome.
Table III. Surgical results.

\begin{tabular}{lcc}
\hline & $\begin{array}{c}\text { mFOLFOXIRI } \\
\mathrm{n}=49(\%)\end{array}$ & $\begin{array}{c}\text { XELOX/SOX } \\
\mathrm{n}=37(\%)\end{array}$ \\
\hline Operative procedures & & \\
$\quad$ Low anterior resection & $25(51.0)$ & $11(29.7)$ \\
$\quad$ Intersphincteric resection & $11(22.4)$ & $22(59.4)$ \\
Total pelvic exenteration & $3(6.1)$ & 0 \\
Hartmann & 0 & $1(2.7)$ \\
Miles & $10(20.4)$ & $3(8.1)$ \\
$\quad$ Lateral lymph node dissection & $13(26.5)$ & $12(32.4)$ \\
Residual tumor classification & & \\
$\quad$ R0/R1/R2 & $49 / 0 / 0$ & $37 / 0 / 0$ \\
\hline
\end{tabular}

Table IV. Tumor response.

\begin{tabular}{lccc}
\hline & $\begin{array}{c}\text { mFOLFOXIRI } \\
\mathrm{n}=49(\%)\end{array}$ & $\begin{array}{c}\text { XELOX/SOX } \\
\mathrm{n}=37(\%)\end{array}$ & $p$-Value \\
\hline $\begin{array}{c}\text { Tumor regression } \\
\text { grading (JSCCR) } \\
0 / 1 \mathrm{a} / 1 \mathrm{~b} / 2 / 3\end{array}$ & $0 / 19(38.7) /$ & $1(2.7) / 11(29.7) /$ & \\
& $12(24.5) / 16(32.6) /$ & $10(27.0) / 10(27.0) /$ & \\
& $2(4.1)$ & $5(13.5)$ & 0.8236 \\
$\begin{array}{l}\text { Pathological } \\
\text { complete response }\end{array}$ & $2(4.8)$ & $5(13.5)$ & 1 \\
$\begin{array}{l}\text { Pathological } \\
\text { response* }\end{array}$ & $18(36.7)$ & $15(40.5)$ & 1 \\
Downstaging & $31(63.2)$ & $31(83.8)$ & 0.0516 \\
\hline
\end{tabular}

JSCCR: Japanese Society for Cancer of the Colon and Rectum (18). *over two-thirds affected area.

Safety. Table V lists the adverse events. Frequent grade 3 or 4 adverse events were: i) leukopenia ( $n=14,28.6 \%)$, ii) neutropenia $(n=22,44.9 \%)$, iii) thrombocytopenia $(n=4$, $8.2 \%)$, iv) febrile neutropenia $(n=4,8.2 \%)$, and $v)$ anorexia $(\mathrm{n}=3,6.1 \%)$ in the mFOLFOXIRI group, whereas neutropenia $(n=3,8.1 \%)$ and diarrhea $(n=2,5.4 \%)$ were the 
Table V. Treatment exposure.

\begin{tabular}{|c|c|c|c|c|}
\hline & \multicolumn{2}{|c|}{$\begin{array}{c}\text { mFOLFOXIRI } \\
\mathrm{n}=49(\%)\end{array}$} & \multicolumn{2}{|c|}{$\begin{array}{c}\text { XELOX/SOX } \\
\mathrm{n}=37(\%)\end{array}$} \\
\hline & All grades & Grade $3 / 4$ & All grades & Grade $3 / 4$ \\
\hline \multicolumn{5}{|l|}{ Hematologic } \\
\hline Leukopenia & $32(65.3)$ & $14(28.6)$ & $10(27.0)$ & 0 \\
\hline Neutropenia & $34(69.4)$ & $22(44.9)$ & $26(70.2)$ & $3(8.1)$ \\
\hline Thrombocytopenia & $20(40.1)$ & $4(8.2)$ & $18(48.6)$ & $1(2.7)$ \\
\hline Anemia & $35(71.4)$ & 0 & $13(35.1)$ & 0 \\
\hline Febrile neutropenia & $4(8.2)$ & $4(8.2)$ & 0 & 0 \\
\hline \multicolumn{5}{|l|}{ Non-hematologic } \\
\hline Fatigue & $28(57.1)$ & $1(2.0)$ & $16(43.2)$ & $1(2.7)$ \\
\hline Anorexia & $34(69.4)$ & $3(6.1)$ & $14(37.8)$ & 0 \\
\hline Nausea & $30(61.2)$ & $1(2.0)$ & $15(40.5)$ & 0 \\
\hline Diarrhea & $21(42.9)$ & $1(2.0)$ & $9(24.3)$ & $2(5.4)$ \\
\hline Stomatitis & $11(22.4)$ & $1(2.0)$ & $4(10.8)$ & 0 \\
\hline Peripheral neutropenia & $27(55.1)$ & $1(2.0)$ & $28(75.7)$ & 0 \\
\hline AST/ALT increase & $23(47.0)$ & $1(2.0)$ & $15(40.5)$ & 0 \\
\hline Vomiting & $8(16.3)$ & 0 & $1(2.7)$ & 0 \\
\hline Hand-foot syndrome & $3(6.1)$ & 0 & $10(27.0)$ & $1(2.7)$ \\
\hline
\end{tabular}

AST: Aspartate aminotransferase; ALT: alanine aminotransferase. Common Terminology Criteria for Adverse Events (CTCAE) version 4.0-Japan Clinical Oncology edition (19).

most common adverse events in the XELOX/SOX group. All adverse events were recovered and there were no treatmentrelated deaths in either group. Surgical complications are listed in Table VI. Surgical complications of grade IIIa or worse that needed invasive treatment were: i) anastomotic leak (mFOLFOXIRI group $\mathrm{n}=2,4.1 \%$; XELOX/SOX group $\mathrm{n}=3,8.1 \%)$, ii) pelvic abscess (mFOLFOXIRI group $\mathrm{n}=1$, $2.0 \%$; XELOX/SOX group $\mathrm{n}=2,5.4 \%$ ), and iii) wound infection (mFOLFOXIRI group $\mathrm{n}=2,4.1 \%$; XELOX/SOX group $\mathrm{n}=0,0 \%)$.

\section{Discussion}

To our knowledge, this study is the first report that compares the efficacy of mFOLFOXIRI with that of XELOX/SOX as neoadjuvant chemotherapy without radiation in patients with LARC. Our data shows that the rates of pathological response (defined as over two-third affected tumor area) are comparable between the mFOLFOXIRI group with $36.7 \%$ (including $4.8 \%$ with $\mathrm{pCR}$ ) and the XELOX/SOX group with $40.5 \%$ (including $13.5 \%$ with pCR) in the group.

In a previous study, a triplet regimen showed cancer higher response rates compared to a doublet regimen in metastatic colorectal, according to the Response Evaluation Criteria in Solid Tumors (RECIST) (15). Therefore, we assumed that mFOLFOXIRI would further improve the regression of the pathological tumor. However, our study did not reveal significant differences in the rates of pathological response between triplet and doublet regimens. Regarding the reasons

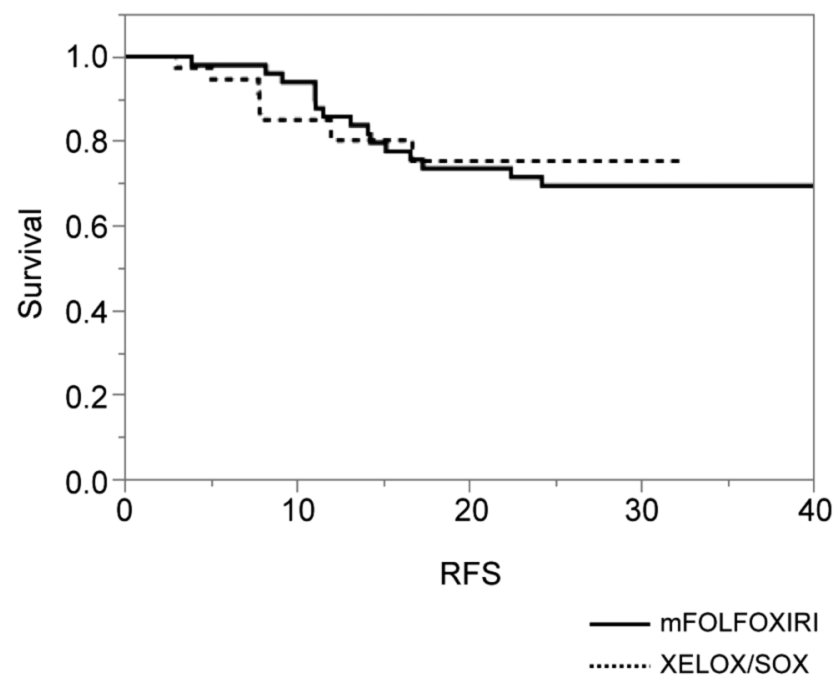

Figure 2. Recurrence free survival (RFS).

for comparable tumor regression in both regimens, we suggest that mFOLFOXIRI might be less effective than expected. In fact, the randomized phase II OLIVIA study, which compared mFOLFOX6 plus bevacizumab with mFOLFOXIRI plus bevacizumab in patients with colorectal cancer and unresectable liver metastasis at baseline, has demonstrated comparable pathological response rates: $52 \%$ in mFOLFOXIRI plus bevacizumab vs. 57\% in mFOLFOX plus bevacizumab (21). In adjuvant settings for colorectal cancer, 
Table VI. Surgical complications.

\begin{tabular}{|c|c|c|c|c|}
\hline & \multicolumn{2}{|c|}{$\begin{array}{c}\text { mFOLFOXIRI } \\
\mathrm{n}=49(\%)\end{array}$} & \multicolumn{2}{|c|}{$\begin{array}{c}\text { XELOX/SOX } \\
\mathrm{n}=37(\%)\end{array}$} \\
\hline & All grades & $>$ Grade IIIa & All grades & $>$ Grade IIIa \\
\hline Wound infection & $4(8.2)$ & $2(4.1)$ & $1(2.7)$ & 0 \\
\hline Pelvic abscess & $5(10.2)$ & $1(2.0)$ & $4(10.8)$ & $2(5.4)$ \\
\hline Anastomotic leak & $4(8.2)$ & $2(4.1)$ & $7(18.9)$ & $3(8.1)$ \\
\hline Urinary tract infection & $9(18.3)$ & 0 & $4(10.8)$ & 0 \\
\hline Ileus & $8(16.3)$ & $3(6.1)$ & $3(8.1)$ & $1(2.7)$ \\
\hline Urinary tract disorder & $5(10.2)$ & 0 & $2(5.4)$ & 0 \\
\hline \multirow[t]{7}{*}{ Others (number of patients) } & Enteritis (3) & Iliac aneurysm (1) & Inflammation (5) & Ureteral injury (2) \\
\hline & Cholecystitis (2) & Intestinal fistula (1) & Postoperative bleeding (2) & \\
\hline & Chylorrhea (2) & & Neuropathy (2) & \\
\hline & & & Vulvar infection (1) & \\
\hline & & & Lymphatic leak (1) & \\
\hline & & & Urinary anastomotic leak (1) & \\
\hline & & & Postoperative pain (1) & \\
\hline
\end{tabular}

Clavien-Dindo criteria version 2.0-Japan Clinical Oncology edition (20).

Table VII. Comparison of efficacies among neoadjuvant chemotherapy regimens.

\begin{tabular}{|c|c|c|c|c|c|c|c|c|c|c|c|c|}
\hline & Pts & Regimen & $\mathrm{T}$ factor & Location & $\mathrm{N}+$ & $\begin{array}{c}\text { MFT } \\
\text { (months) }\end{array}$ & $\begin{array}{c}\text { R0 resection } \\
(\%)\end{array}$ & $\begin{array}{l}\mathrm{pCR} \\
(\%)\end{array}$ & $\begin{array}{l}\mathrm{pR} \\
(\%)\end{array}$ & $\begin{array}{l}\mathrm{LR} \\
(\%)\end{array}$ & $\begin{array}{l}\mathrm{DM} \\
(\%)\end{array}$ & Outcomes \\
\hline $\begin{array}{l}\text { Uehara et al. } \\
\text { (25) }\end{array}$ & 32 & $\begin{array}{l}\text { XELOX } \\
- \text { Bmab }\end{array}$ & $\begin{array}{c}\text { T4a: } \\
9(28 \%) \\
\text { T4b: } \\
10(31 \%)\end{array}$ & $\begin{array}{c}<5: \\
16(50 \%) \\
5 \leq-<9: \\
11(34 \%) \\
\geq 9: \\
5(15 \%)\end{array}$ & $\begin{array}{c}26 \\
(81 \%)\end{array}$ & N/A & 84.3 & 13.3 & $36.7^{*}$ & N/A & N/A & N/A \\
\hline $\begin{array}{l}\text { Schrag et al. } \\
\text { (9) }\end{array}$ & 32 & $\begin{array}{l}\text { FOLFOX } \\
- \text { Bmab }\end{array}$ & $\mathrm{T} 4: 0 \%$ & no stated & $\begin{array}{c}23 \\
(71 \%)\end{array}$ & 54 & 100 & 25 & N/A & 0 & 12.5 & $\begin{array}{c}84 \\
(4 y-D F S)\end{array}$ \\
\hline $\begin{array}{l}\text { Deng et al. } \\
\text { (10) }\end{array}$ & 152 & FOLFOX & $\begin{array}{c}\text { T4a: } \\
32(22 \%) \\
\text { T4b: } \\
5(3 \%)\end{array}$ & $\begin{array}{c}<5: \\
70(42 \%) \\
5 \leq-<10: \\
86(52 \%) \\
\geq 10: \\
9(5 \%)\end{array}$ & N/A & 45.2 & 89.4 & 6.5 & $32.9 * *$ & 8.3 & N/A & $\begin{array}{c}73.5 \\
(3 y-D F S)\end{array}$ \\
\hline $\begin{array}{l}\text { This } \\
\text { study }\end{array}$ & 49 & mFOLFOXIRI & $\begin{array}{c}\text { T4a: } \\
9(18 \%), \\
\text { T4b: } \\
10(20 \%)\end{array}$ & $\begin{array}{c}\mathrm{Ra}: \\
4(8 \%) \\
\mathrm{Rb}: \\
44(89 \%)\end{array}$ & $\begin{array}{c}36 \\
(73 \%)\end{array}$ & 30.9 & 100 & 3.9 & $36.7 *$ & 2 & 24.5 & $\begin{array}{c}85.7 \\
(1 y-R F S) \\
69.4 \\
(3 y-R F S)\end{array}$ \\
\hline $\begin{array}{l}\text { This } \\
\text { study }\end{array}$ & 37 & $\begin{array}{c}\text { XELOX } \\
\text { SOX }\end{array}$ & $\begin{array}{c}\text { T4a: } \\
9(24 \%), \\
\text { T4b: } \\
4(11 \%)\end{array}$ & $\begin{array}{c}\mathrm{Ra}: \\
0 \\
\mathrm{Rb}: \\
37(100 \%)\end{array}$ & $\begin{array}{c}27 \\
(73 \%)\end{array}$ & 8 & 100 & 13.5 & $40.5^{*}$ & 2.7 & 18.9 & $\begin{array}{c}76.5 \\
(1 \mathrm{y}-\mathrm{RFS}) \\
\text { N/A }\end{array}$ \\
\hline
\end{tabular}

Pts: Patients; N+: lymph-node metastasis; MFT: median follow up time; pCR: pathological complete response; pR: pathological response; LR: local recurrence; DM: distant metastasis; Bmab: bevazizumab; Ra: middle rectum; Rb: lower rectum, N/A: not applicable; DFS: disease-free survival; RFS: recurrence-free survival. *Tumor affected area over two-third. **Tumor regression grading (TRG) of 0 or 1 , which was evaluated semiquantitatively on a scale of 0 to 3 (complete to poor response, respectively) according to National Comprehensive Cancer Network guidelines (28).

oxaliplatin is one of the key drugs in combination with fluoropyrimidine-based regimens $(14,15)$, whereas irinotecan has failed to demonstrate its efficacy (22). Here, the dose intensity of oxaliplatin in the first four weeks of treatment were $40.4 \mathrm{mg} / \mathrm{m}^{2} /$ week in mFOLFOXIRI and 63.9 $\mathrm{mg} / \mathrm{m}^{2} /$ week in XELOX/SOX, which might cause no significant differences in pathological response rates between triplet and doublet treatments. 
Regarding the toxicity, the rate of grade 3 or 4 events was higher in the mFOLFOXIRI group compared to the XELOX/SOX group. Especially, hematologic toxicities and febrile neutropenia were much more frequent in the mFOLFOXIRI compared to the XELOX/SOX group, although the neutropenia frequency in our study was similar to that seen in a previous mFOLFOXIRI study with Japanese patients (17). On the other hand, the toxicities in the XELOX/SOX group were equivalent to that detected in previous doublet treatment studies $(11-12,25)$.

Table VII summarizes the findings of other neoadjuvant chemotherapy studies. The comparison of the pathological response rate is difficult because the definition of pathological response differs among studies. However, the pCR or R0 resection rates of our study were favorable despite the fact that our study enrolled more high-risk patients than other studies; in the mFOLFOXRI and XELOX/SOX groups the T4 rates were $38 \%$ and $35 \%$, respectively, and the $\mathrm{Rb}$ rates were $92 \%$ and $100 \%$, respectively. Although the pCR rates were higher for chemotherapy with radiation compared to chemotherapy alone, the rates of local recurrence and 3-year disease-free survival in the FOWARC study were similar between with or without radiation $(9,10)$. Considering the toxicity caused by radiation (7), neoadjuvant chemotherapy for LARC is promising and could potentially improve survival outcomes.

In the present study, we did not add biological drugs as neoadjuvant treatment because several studies have demonstrated that the additional use of biological drugs does not improve survival $(23,24)$ and their use might increase surgical complications $(25,26)$. Furthermore, the phase II FOxTROT study, which investigated the effects of additional cetuximab as neoadjuvant chemotherapy, has shown no additional improvement with the use of cetuximab in terms of tumor regression (27). However, additional testing with bevacizumab is warranted given that it is used to deliver cytotoxic drugs to cancer cells, and, thus, is expected to improve tumor regression.

There are several limitations to our study. First, this study was a relatively small retrospective study at a single institution. Although our study was not a randomized trial, the patient characteristics were similar between the two study groups. Second, we could not compare the long-term benefits between the two groups because the follow-up period in the XELOX/SOX group was too short. Therefore, our results are preliminary regarding recurrence and survival endpoints Third, we did not investigate the efficacy and safety of the original FOLFOXIRI dosage. The reason for choosing the modified FOLFOXIRI dosage as neoadjuvant therapy was that the rate of tumor shrinkage has been shown to be similar between the original and modified dosage in Japanese patients, despite the decreased incidence of grade 3 or 4 neutropenia and febrile neutropenia $(16,17)$. The
FOLFOXIRI regimen seemed not to be acceptable as a neoadjuvant setting. Fourth, we did not examine the BRAF status of the enrolled patients.

In conclusion, both mFOLFOXIRI and XELOX/SOX showed favorable $\mathrm{R} 0$ resection rates. Although there was no significant difference in the pathological response rate between the two regimens, the mFOLFOXIRI regimen was more toxic. Compared to mFOLFOXIRI, XELOX/SOX should be recommended as neoadjuvant chemotherapy in patients with LARC.

\section{Conflicts of Interest}

The Authors have no conflicts of interest to declare.

\section{Authors' Contributions}

Conception and design: Hiroyuki Kodama, Tetsuji Terazawa, Kazuhide Higuchi. Collection of data: Hiroyuki Kodama, Tetsuji Terazawa, Yasunobu Ishizuka, Hiroki Yukami, Masahiko Aoki, Takahiro Miyamoto, Toshifumi Yamaguchi, Fukutaro Shimamoto, Takayuki Kii, Masahiro Goto, Hiroki Hamamoto, Wataru Osumi, Masashi Yamamoto, Keitaro Tanaka, Jyunji Okuda, Kazuhisa Uchiyama. Data analysis: Hiroyuki Kodama, Testuji Terazawa. Manuscript writing: Hiroyuki Kodama, Tetsuji Terazawa. All Authors read and approved the final manuscript.

\section{Acknowledgements}

The Authors would like to thank the patients who participated in this study and their families as well as the staff members. We would like to thank Editage (www.editage.com) for English language editing.

\section{References}

1 Jacques F, Isabelle S, Rajesh D, Eser S, Mathers C, Rebelo M, Parkin DM, Forman D and Bray F: Cancer Incidence and Mortality Worldwide: Sources, Methods and Major Patterns in GLOBOCAN 2012. Int J Cancer 136(5): 359-386, 2015. PMID: 25220842. DOI: $10.1002 / \mathrm{ijc} .29210$

2 Khrizman P, Niland JC, ter Veer A, Milne D, Bullard Dunn K, Carson WE 3 $3^{\text {rd }}$, Engstrom PF, Shibata S, Skibber JM, Weiser MR, Schrag D and Benson AB $3^{\text {rd: Postoperative adjuvant }}$ chemotherapy use in patients with stage II/III rectal cancer treated with neoadjuvant therapy: A National Comprehensive Cancer Network analysis. J Clin Oncol 31(1): 30-38, 2013. PMID: 23169502. DOI: 10.1200/JCO.2011.40.3188

3 Benson AB 3rd, Venook AP, Bekaii-Saab T, Chan E, Chen YJ, Cooper HS, Engstrom PF, Enzinger PC, Fenton MJ, Fuchs CS, Grem JL, Grothey A, Hochster HS, Hunt S, Kamel A, Kirilcuk N, Leong LA, Lin E, Messersmith WA, Mulcahy MF, Murphy JD, Nurkin S, Rohren E, Ryan DP, Saltz L, Sharma S, Shibata D, Skibber JM, Sofocleous CT, Stoffel EM, Stotsky-Himelfarb E, Willett CG, Gregory KM and Freedman-Cass D: Rectal cancer, version 2.2015. J Natl Compr Canc Netw 13(6): 719728, 2015. PMID: 26085388. DOI: 10.6004/jncen.2015.0087

4 Glimelius B, Tiret E, Cervantes A, Arnold D and ESMO Guidelines Working Group: Rectal cancer: ESMO Clinical 
Practice Guidelines for diagnosis, treatment and follow-up. Ann Oncol 24(Suppl 6): vi81-8, 2013. PMID: 24078665. DOI: 10.1093/annonc/mdt240

5 Sauer R, Becker H, Hohenberger W, Rödel C, Wittekind C, Fietkau R, Martus P, Tschmelitsch J, Hager E, Hess CF, Karstens JH, Liersch T, Schmidberger H and Raab R; German Rectal Cancer Study Group: Preoperative versus postoperative chemoradiotherapy for rectal cancer. N Engl J Med 351(17): 1731-1740, 2004. PMID: 15496622. DOI: 10.1056/NEJMoa040694

6 Sauer R, Liersch T, Merkel S, Fietkau R, Hohenberger W, Hess C, Becker H, Raab HR, Villanueva MT, Witzigmann H, Wittekind C, Beissbarth T and Rödel C: Preoperative versus postoperative chemoradiotherapy for locally advanced rectal cancer: results of the German CAO/ARO/AIO-94 randomized phase III trial after a median follow-up of 11 years. J Clin Oncol 30(16): 1926-1933, 2012. PMID: 22529255. DOI: 10.1200/JCO. 2011.40.1836

7 Peeters KC, van de Velde CJ, Leer JW, Martijn H, Junggeburt JM, Kranenbarg EK, Steup WH, Wiggers T, Rutten HJ and Marijnen CA: Late side effects of short-course preoperative radiotherapy combined with total mesorectal excision for rectal cancer: increased bowel dysfunction in irradiated patients - a Dutch colorectal cancer group study. J Clin Oncol 23(25): 61996206, 2005. PMID: 16135487. DOI: 10.1200/JCO.2005.14.779

8 Schrag D, Weiser MR, Goodman KA, Gonen M, Hollywood E, Cercek A, Reidy-Lagunes DL, Gollub MJ, Shia J, Guillem JG, Temple LK, Paty PB and Saltz LB: Neoadjuvant chemotherapy without routine use of radiation therapy for patients with locally advanced rectal cancer: a pilot trial. J Clin Oncol 32(6): 513518, 2014. PMID: 24419115. DOI: 10.1200/JCO.2013.51.7904

9 Deng Y, Chi P, Lan P, Wang L, Chen W, Cui L, Chen D, Cao J, Wei H, Peng X, Huang Z, Cai G, Zhao R, Huang Z, Xu L, Zhou H, Wei Y, Zhang H, Zheng J, Huang Y, Zhou Z, Cai Y, Kang L, Huang M, Peng J, Ren D and Wang J: Modified FOLFOX6 with or without radiation versus fluorouracil and leucovorin with radiation in neoadjuvant treatment of locally advanced rectal cancer: Initial results of the Chinese FOWARC multicenter, open-label, randomized three-arm phase III trial. J Clin Oncol 34(27): 3300-3307, 2016. PMID: 27480145. DOI: 10.1200/ JCO.2016.66.6198

10 Deng Y, Chi P, Lan P, Wang L, Chen W, Cui L, Chen D, Cao J, Wei H, Peng X, Huang Z, Cai G, Zhao R, Huang Z, Xu L, Zhou H, Wei Y, Zhang H, Zheng J, Huang Y, Zhou Z, Cai Y, Kang L, Huang M, Wu X, Peng J, Ren D and Wang J: Neoadjuvant modified FOLFOX6 with or without radiation versus fluorouracil plus radiation for locally advanced rectal cancer: Final results of the Chinese FOWARC trial. J Clin Oncol 37(34): 3223-3233, 2019. PMID: 31557064. DOI: 10.1200/JCO. 18.02309

11 Yamada Y, Takahari D, Matsumoto H, Baba H, Nakamura M, Yoshida K, Yoshida M, Iwamoto S, Shimada K, Komatsu Y, Sasaki Y, Satoh T, Takahashi K, Mishima H, Muro K, Watanabe M, Sakata Y, Morita S, Shimada Y and Sugihara K: Leucovorin, fluorouracil, and oxaliplatin plus bevacizumab versus $\mathrm{S}-1$ and oxaliplatin plus bevacizumab in patients with metastatic colorectal cancer (SOFT): an open-label, non-inferiority, randomised phase 3 trial. Lancet Oncol 14(13): 1278-1286, 2013. PMID: 24225157. DOI: 10.1016/S1470-2045(13)70490-X

12 Cassidy J, Clarke S, Díaz-Rubio E, Scheithauer W, Figer A, Wong R, Koski S, Rittweger K, Gilberg F and Saltz L: XELOX vs. FOLFOX-4 as first-line therapy for metastatic colorectal cancer: NO16966 updated results. Br J Cancer 105(1): 58-64, 2011. PMID: 21673685. DOI: 10.1038/bjc.2011.201

13 Grothey A, Sobrero AF, Shields AF, Yoshino T, Paul J, Taieb J, Souglakos J, Shi Q, Kerr R, Labianca R, Meyerhardt JA, Vernerey D, Yamanaka T, Boukovinas I, Meyers JP, Renfro LA, Niedzwiecki D, Watanabe T, Torri V, Saunders M, Sargent DJ, Andre T and Iveson T: Duration of adjuvant chemotherapy for stage III colon cancer. N Engl J Med 378(13): 1177-1188, 2018. PMID: 29590544. DOI: 10.1056/NEJMoa1713709

14 Yoshino T, Yamanaka T, Oki E, Kotaka M, Manaka D, Eto T, Hasegawa J, Takagane A, Nakamura M, Kato T, Munemoto Y, Takeuchi S, Bando H, Taniguchi H, Gamoh M, Shiozawa M, Mizushima T, Saji S, Maehara Y, Ohtsu A and Mori M: Efficacy and long-term peripheral sensory neuropathy of $3 \mathrm{vs} .6$ months of oxaliplatin-based adjuvant chemotherapy for colon cancer: The ACHIEVE phase 3 randomized clinical trial. JAMA Oncol 5(11): 1574-1581, 2019. PMID: 31513248. DOI: 10.1001/ jamaoncol.2019.2572

15 Loupakis F, Cremolini C, Masi G, Lonardi S, Zagonel V, Salvatore L, Cortesi E, Tomasello G, Ronzoni M, Spadi R, Zaniboni A, Tonini G, Buonadonna A, Amoroso D, Chiara S, Carlomagno C, Boni C, Allegrini G, Boni L and Falcone A: Initial therapy with FOLFOXIRI and bevacizumab for metastatic colorectal cancer. N Engl J Med 371(17): 1609-1618, 2014. PMID: 25337750. DOI: 10.1056/NEJMoa1403108

16 Oki E, Kato T, Bando H, Yoshino T, Muro K, Taniguchi H, Kagawa Y, Yamazaki K, Yamaguchi T, Tsuji A, Iwamoto S, Nakayama G, Emi Y, Touyama T, Nakamura M, Kotaka M, Sakisaka H, Yamanaka $\mathrm{T}$ and Kanazawa A: A multicenter clinical phase II study of FOLFOXIRI plus bevacizumab as firstline therapy in patients with metastatic colorectal cancer: QUATTRO study. Clin Colorectal Cancer 17(2): 147-155, 2018. PMID: 29530335. DOI: 10.1016/j.clcc.2018.01.011

17 Satake H, Sunakawa Y, Miyamoto Y, Nakamura M, Nakayama H, Shiozawa M, Makiyama A, Kobayashi K, Kubota Y, Mori M, Kotaka M, Takagane A, Gotoh M, Takeuchi M, Fujii M, Ichikawa W and Sekikawa T: A phase II trial of 1st-line modified-FOLFOXIRI plus bevacizumab treatment for metastatic colorectal cancer harboring RAS mutation: JACCRO CC-11. Oncotarget 9(27): 18811-18820, 2018. PMID: 29721163. DOI: 10.18632 /oncotarget.24702

18 Japanese Society for Cancer of the Colon and Rectum: Japanese Classification of Colorectal, Appendiceal, and Anal Carcinoma: the 3d English Edition [Secondary Publication]: J Anus Rectum Colon 3(4): 175-195, 2019. PMID: 31768468. DOI: $10.23922 /$ jarc.2019-018

19 Japan Clinical Oncology Group: National Institute Common Terminology Criteria for Adverse Events version 4.0 -Japan Clinical Oncology Group edition. Available at: http://www.jcog. jp/doctor/tool/CTCAEv4J_20170912_v20_1.pdf

20 Japan Clinical Oncology Group: Clavien Dindo Classification version 2.0 - Japan Clinical Oncology Group edition. Available at: http://www.jcog.jp/doctor/tool/JCOG_Clavian-Dindo_ver2.0.pdf \#search $=\% 27$ clavian+dindo $+\mathrm{j} \operatorname{cog} \% 27$

21 Gruenberger T, Bridgewater J, Chau I, García Alfonso P, Rivoire M, Mudan S, Lasserre S, Hermann F, Waterkamp D and Adam R: Bevacizumab plus mFOLFOX-6 or FOLFOXIRI in patients with initially unresectable liver metastases from colorectal cancer: the OLIVIA multinational randomised phase II trial. Ann 
Oncol 26(4): 702-708, 2015. PMID: 25538173. DOI: 10.1093/ annonc/mdu580

22 Saltz LB, Niedzwiecki D, Hollis D, Goldberg RM, Hantel A, Thomas JP, Fields AL and Mayer RJ: Irinotecan fluorouracil plus leucovorin is not superior to fluorouracil plus leucovorin alone as adjuvant treatment for stage III colon cancer: results of CALGB 89803. J Clin Oncol 25(23): 3456-3461, 2007. PMID: 17687149. DOI: $10.1200 / J C O .2007 .11 .2144$

23 Dewdney A, Cunningham D, Tabernero J, Capdevila J, Glimelius B, Cervantes A, Tait D, Brown G, Wotherspoon A, Gonzalez de Castro D, Chua YJ, Wong R, Barbachano Y, Oates $\mathrm{J}$ and Chau I: Multicenter randomized phase II clinical trial comparing neoadjuvant oxaliplatin, capecitabine, and preoperative radiotherapy with or without cetuximab followed by total mesorectal excision in patients with high-risk rectal cancer (EXPERT-C). J Clin Oncol 30(14): 1620-1627, 2012. PMID: 22473163. DOI: 10.1200/JCO.2011.39.6036

24 Horisberger K, Treschl A, Mai S, Barreto-Miranda M, Kienle P, Ströbel P, Erben P, Woernle C, Dinter D, Kähler G, Hochhaus A, Post S, Willeke F, Wenz F and Hofheinz RD; MARGIT (Mannheimer Arbeitsgruppe für Gastrointestinale Tumoren): Cetuximab in combination with capecitabine, irinotecan, and radiotherapy for patients with locally advanced rectal cancer: results of a phase II MARGIT trial. Int J Radiat Oncol Biol Phys 74(5): 1487-1493, 2009. PMID: 19131187. DOI: 10.1016/ j.ijrobp.2008.10.014

25 Uehara K, Hiramatsu K, Maeda A, Sakamoto E, Inoue M, Kobayashi S, Tojima Y, Yoshioka Y, Nakayama G, Yatsuya H, Ohmiya N, Goto H and Nagino M: Neoadjuvant oxaliplatin and capecitabine and bevacizumab without radiotherapy for poor-risk rectal cancer: N-SOG 03 phase II trial. Jpn J Clin Oncol 43(10): 964-971, 2013. PMID: 23935207. DOI: 10.1093/jjco/hyt115
26 Hasegawa J, Nishimura J, Mizushima T, Miyake Y, Kim HM, Takemoto H, Tamagawa H, Noura S, Fujii M, Fujie Y, Kato T, Miwa H, Takemasa I, Ikeda M, Yamamoto H, Sekimoto M, Nezu $\mathrm{R}$, Doki $\mathrm{Y}$ and Mori M: Neoadjuvant capecitabine and oxaliplatin (XELOX) combined with bevacizumab for high-risk localized rectal cancer. Cancer Chemother Pharmacol 73(5): 1079-1087, 2014. PMID: 24595805. DOI: 10.1007/s00280-0142417-9

27 Seymour MT, Morton D and International FOxTROT Trial Investigators: FOxTROT: an international randomised controlled trial in 1052 patients (pts) evaluating neoadjuvant chemotherapy (NAC) for colon cancer. J Clin Oncol 37(suppl 15): abstract 3504, 2019. DOI: 10.1200/JCO.2019.37.15_suppl.3504

28 Ryan R, Gibbons D, Hyland JM, Treanor D, White A, Mulcahy HE, O'Donoghue DP, Moriarty M, Fennelly D and Sheahan K: Pathological response following long-course neoadjuvant chemoradiotherapy for locally advanced rectal cancer. Histopathology 47(2): 141-146, 2005. PMID: 16045774. DOI: $10.1111 / \mathrm{j} .1365-2559.2005 .02176 . \mathrm{x}$
Received October 29, 2020

Revised December 12, 2020

Accepted December 24, 2020 